building to avoid noise and vibration from other activities. Besides regular laboratory space, this includes a large 'dead' room for response measurements of microphones and loud speakers, two 'live' rooms or reverberation chambers for transmission and absorption measurements and a small auditorium.

The auditorium was built primarily for experiments in auditorium acoustics and its construction follows the latest practice in acoustic treatment. To break up reflections, the side walls are splayed and the rear wall is sloped away from the seats for the same purpose. Panelling at the rear of the room, and that on the adjacent side walls and ceiling, is perforated and backed by absorbing material to reduce reflected sound from these areas. There are 363 seats. Each is upholstered to absorb about as much sound when not occupied as would a person, thus maintaining the same reverberation characteristics in the room whether it is empty or filled to capacity. For the convenience of the audience, the seats are widely separated in accord with European practice. Although made quite reverberant for musical reproduction, the excellent acoustic characteristics of the listening room make it exceptionally satisfactory for speaking. There are no windows. Decorative lights are mounted on the side walls. Recessed lamps are distributed uniformly over the ceiling and spotlights illuminate the platform and speaker. These groups of lights can be used separately or in combination and most of them can also be dimmed.

A technical library is an indispensable adjunct to a research laboratory, and provision has been made at Murray Hill for this need by transferring about eight thousand volumes from the main library at New York City. Reference books and technical periodicals make up most of the collection, since other books are always available on request from New York. The stacks are made of sheet steel with adjustable metal shelves, slotted to prevent the accumulation of dust, and the front edge of the lowest two shelves is tilted upward to aid in reading titles. Along two sides of the room there is a row of small study carrells with chair, writing-table and shelves for the convenience of those who have long assignments and who wish to have several reference books immediately at hand. This is a valuable feature, because it provides privacy and avoids the confusion and disturbance of a common study table.

The additional facilities provided at the Murray Hill Laboratories are in great demand in the present war emergency, and are contributing effectively toward the solution of many problems posed by the conflict. Practically the entire staff is now engaged in war work.

\section{A MYRMECOPHILOUS WOODLOUSE}

$I^{\mathbb{*}}$ the spring of 1938 Prof. G. E. Hutchinson found a small white blind myrmecophilous sowbug in North Branford, Connecticut. The species was afterwards found in ants' nests in a small tract of country several miles in area round about the original locality, and within the Mt. Carmel region of Hamden, Conn., some nine miles from North Branford.

Prof. J. L. Brooks, in a recent paper (Ecology, 23, No. $4,427-37 ; 1942)$, points out that in 1921 there were five valid species of Platyarthrus, four of these being restricted to the Mediterranean region, and only one, $P$. hoffmanseggi Brdt., being found throughout Europe. In 1931 Archangeli described a new species from the Canary Islands, and in 1934 Demianowicz reported two more from Bessarabia. The Connecticut species was identified as Platyarthrus hoffmanseggi Brdt. Its distribution is given as Upper Italy, Spain, France, Switzerland, Holland, Germany, Denmark, Austria, Hungary, Russia and the British Isles.

North Branford, Conn., is the first place in the New World where a Platyarthrus has been found. In all probability it was accidentally introduced from Europe.

All the species of this genus are myrmecophilous, but most of the observations concerning them are confined to the species in question. Although Was. mann considered $P$. hoffmanseggi to be pan-myrmecophilous, Prof. Brooks says that it has not been recorded with other ants than those he lists. $\mathrm{He}$ points out that the records from the Continent are from Archangeli ; and for England from Donisthorpe, and Webb and Sillem. $\mathrm{He}$ is indebted to Prof. Neal A. Weber for the names of the ants with which it has been found in America.

Prof. Brooks considers that the data indicate the existence of some factor or factors governing the presence of this sowbug only in the nests of certain species in any region. This is possibly the case; but $I$ am inclined to think that if collectors had always recorded the presence of the crustacean when they had seen it, or had specially looked for it, the number both of localities and species of ants would be considerably greater.

As Mr. Brooks is not a myrmecologist himself, he can be excused for some errors in his list. of ants. There are no species called Myrmica rufa, or Formica flara. Also the genus Atta F. only occurs in Texas, Mexico, Central and South America, and has certainly never been recorded from Europe. Atta cephalotes L., not cephalotis, is recorded from the basin of the Amazon, Columbia, Central America, and Mexica. Furthermore, as Prof. Brooks says himself, he has used the generic nomenclature adopted by the Committee of the Royal Entomological Society of London, and thus has been 'let down' about Acanthomyops. For example, A. fuliginosus Latr. belongs to the subgenus Dendrolasius Ruzsky. It could be called, according to whether one accepts Lasius or Acanthomyops as the genus, either Lasius (Dendrolasius) fuliginosus Latr., or Acanthomyops (Dendrolasius) fuliginosus Latr., but never Lasius (Acanthomyops) (see Donisthorpe, Ent. Record, 49, 143 ; 1937). Also flavus F., and umbratus Nyl., belong to the subgenus Chtonolasius Ruzsky. The variety of Formica fusca L. is glebaria Nyl., not gleboris.

We now come to Prof. Brooks' experimental work to endeavour to discover the factors involved in the relationship between the woodlouse and its hosts. These are of a delicate, ingenious, and painstaking nature. They are intended to test the response to light (phototaxis), unoriented response (photoklinokinesis), response to atmospheric humidity gradient, and the reaction to a gradient of formic acid vapour, and are illustrated by diagrams, graphs, histograms, etc. The results are briefly as follows. Platyarthrus hoffmanseggi showed no direct response to light under the conditions used in the experiments. It showed a lower klinokinesis in the light than in the dark, and the klinokinesis of this species was found 
to be much greater than that of the non-myrmecophilous woodlouse Oniscus asellus. It moved towards the humidity end of a humidity gradient, as does also Oniscus asellus. It is attracted towards formic acid vapour, whereas Oniscus asellus avoided it. It was indifferent to acetic acid vapour, but that of propionic acid repulsed it.

In my observation nests I found that Platyarthrus hnffmanseggi always sought the dark chambers of the nest, but this is probably because they are the dampest, and also they are those usually inhabited by the ants themselves.

Prof. Brooks considers that the evidence strongly supports the supposition that Platyarthrus is chiefly found in the nests of those ants which possess an appreciable amount of formic acid. $\mathrm{He}$ says that the question of the food of this species has never been adequately answered. He quotes what I wrote on this subject: "Lord Avebury suggested that it fed on spores of the lower plants, such as would be found in ants' nests. These, however, would not be present in plaster nests, and I believe that the food of this species also, in part at least, consists of the 'boulettes de nettoyage' from the ant's infrabuccal cavity"*; but he points out that Platyarthus has been kept in the laboratory for months away from ants, and has even reproduced itself. He thinks it is obvious that these creatures are not directly dependent on ants, but that the nests of the latter provide an environment in which they have a better ehance of surviving.

A useful list of references is given at the end of the paper, which is a very able contribution towards the life-history of the animal in question. The discovery that it is attracted by the vapour of formic acid is of considerable value.

Horace Donisthorpe.

*"Guests of British Ants", 215-17 (1927).

\section{ELECTROMETALLURGICAL INDUSTRY}

D R. J. W. CUTHBERTSON, of the University of Manchester, gave a lecture on May 19 before the London and South Eastern Counties Section of the Royal Institute of Chemistry on "Recent Advances in Electrometallurgical Industry". $\mathrm{He}$ pointed out that during recent years, and especially since the outbreak of war, development in this field has been very rapid, particularly in the United States, where raw materials are plentiful and there are ample facilities for the production of cheap electrical energy. The possibilities of further expansion both in Great Britain and elsewhere, however, are now being exploited, and the development of the home industry will doubtless be stimulated by the growing realization that, in certain circumstances, electrieal energy can be produced by the modern steam generation station on a basis which compares favourably with the cost of production by a hydroelectric plant.

Electrometallurgy can be subdivided into two main sections covering electrolytic processes and electrothermal processes respectively. The former include extraction, refining, electrodeposition, surface protection and so on. In the extraction field, mention may be made of the enormous expansion in the production of aluminium and magnesium, and of the pioneer work now yielding results in the United States on the electrolytic production of manganese from low-grade ores.

Turning to the sphere of electrodeposition, bright plàting, which was first introduced some years ago, has since made great strides. This is particularly noticeable in the case of nickel and latterly also of zinc. Electrogalvanizing has now to a large extent superseded the old hot-dip process, while considerable progress is being made in the corresponding electrotinning industry. Hard chromium plate is in wide demand throughout the engineering industry as a means of obtaining improved resistance to surface wear and abrasion of metals and alloys. Efforts which continue to be made to find a non-toxic substitute for plating baths of the cyanide type appear to be meeting with some success, more especially as regards the deposition of copper. Recent work on the deposition of aluminium from non-aqueous electrolytes has led to the development of a process which is now being exploited on a semi-industrial scale. Considerable advances have also been recorded in the deposition of alloys-a field which for certain engineering and other applications would appear to offer possibilities.

Until only a very few years ago, electrolytic polishing was almost unknown outside the laboratory, but rapid progress has been made recently in the indus. trial development of this method of surface finishing.

In the electrothermal field the most noteworthy achievement of recent years has probably been the perfecting of the coreless induction furnace ; originally these furnaces were used mainly for melting and alloying, but promising results have also been obtained by using them in refining practice. The use of the coreless furnace as a means of raising the temperature of metals and alloys for purposes of heat treatment is increasing; the versatility of the method is well illustrated by its application to the internal hardening of hollow parts. In the resistance furnace field, developments have largely been confined to improvements in the design and control of units of the closed type intended to be used with special gas atmospheres. Are furnaces have undergone marked changes in design, but apart from the growing demand for electric steel and consequent expansion of plant, there has not been a great deal of change in arc furnace practice during recent years.

\section{THE JOHN INNES HORTICUL- TURAL INSTITUTION}

A USEFUL review of some recent work in A horticultural science is provided by the annual report for 1942 of the John Innes Horticultural Institution (from the Institution, Mostyn Road, Merton Park, S.W.19, March 3943). Mr. M. B. Crane and his colleagues in the Department of Pomology have investigated various factors which affect the production of fruit and seed crops. Dr. D. Lewis finds, for example, that the English cucumber produces seedless fruits when grown at a high temperature, even after the flower has been adequately pollinated. At low temperatures the fruits may be seeded or seedless, according to whether the flowers have been pollinated or not. Mr. A. G. Brown has related the phenology of apple and pear trees to the 